\title{
The Effect of Concurrent Straining on Phase Transformations in NiAl Bronze During the Friction Stir Processing Thermomechanical Cycle
}

\author{
JIANQING SU, SRINIVASAN SWAMINATHAN, SARATH K. MENON, \\ and TERRY R. McNELLEY \\ Equivalent strains up to a value of $\approx 2.7$ were determined by evaluation of the shape changes of \\ the phases in a duplex $\alpha(\mathrm{fcc}) / \beta(\mathrm{bcc})$ microstructure formed ahead of the pin tool extraction site \\ during the friction stir processing (FSP) thermomechanical cycle in a cast NiAl bronze alloy. \\ Correlation of the local strains with volume fractions of the various microstructure constituents \\ in this alloy shows that the concurrent straining of FSP results in acceleration of the $\alpha+\beta \rightarrow \beta$ \\ reaction in the thermomechanically affected zone (TMAZ) ahead of the pin extraction site. The \\ resulting volume fraction of $\beta$ (as determined by the volume fraction of its transformation \\ products formed during post-FSP cooling) corresponds closely to the volume fraction expected \\ for the peak stir zone temperature measured separately by means of thermocouples embedded \\ within the tool pin profile along the tool path. The stir zone (SZ) in this material exhibits near- \\ equilibrium microstructures despite brief dwells near the peak temperature $\left(T_{\text {peak }} \approx 0.95 T_{\text {melt }}\right)$, \\ reflecting large local strains and strain rates associated with this process.
}

DOI: $10.1007 / \mathrm{s} 11661-011-0638-7$

(C) The Author(s) 2011. This article is published with open access at Springerlink.com

\section{INTRODUCTION}

FRICTION stir processing (FSP) is a solid-state technique involving the use of a nonconsumable rotating tool that consists of a cylindrical shoulder region and a projecting, concentric pin of smaller diameter. Initially, the pin is forced against the surface of a deformable work piece so that frictional heating results in softening of the work piece material. Subsequently, additional heating occurs due to adiabatic deformation induced in a column of material that forms around the tool pin. Softening due to the combined effect of these heat sources allows tool penetration until the shoulder comes into contact with the work piece surface. The shoulder acts to constrain upward flow of the deforming material, and additional work piece deformation is induced by the action of the tool shoulder on the work piece surface. When the resulting stir zone attains a sufficient temperature, the tool may be traversed in a predetermined pattern over the surface to process a volume of material defined by the pin tool profile and the processing pattern. FSP is an allied process of friction stir welding $(\mathrm{FSW}){ }^{[1]}$ and both have been conducted on cast as well as wrought metals including alloys of $\mathrm{Al}$ and $\mathrm{Mg}$ as well

JIANQING SU, Senior Postdoctoral Associate, is with the Missouri University of Science and Technology, Rolla, MO 65409. SRINIVASAN SWAMINATHAN, Research Scientist, is with General Electric-Global Research, Bangalore 560066, India. SARATH K. MENON, Research Professor, and TERRY R. McNELLEY, Distinguished Professor, are with the Department of Mechanical and Aerospace Engineering, Naval Postgraduate School, Monterey, CA 93943-5146. Contact e-mail: tmcnelley@nps.edu

Manuscript submitted July 23, 2010.

Article published online February 24, 2011 as higher melting alloys of $\mathrm{Cu}, \mathrm{Fe}$, and Ti. When applied to an as-cast metal such as NiAl bronze, FSP converts the as-cast microstructure to a wrought condition in the absence of macroscopic shape change. ${ }^{[2,3]}$

The FSP thermomechanical cycle involves rapid transients and steep gradients in temperature, strain, and strain rate that, together, depend on tool geometry, work piece constitutive behavior, and processing parameters such as tool rotational speed (rpm) and traversing rate. ${ }^{[4]}$ Direct measurement of the temperature cycle by thermocouples embedded along the tool path within the tool profile in thick plates of as-cast NiAl bronze showed that peak stir zone temperatures are 0.92 to 0.97 $T_{\text {melt }}$ during FSP of this material. ${ }^{[5]}$ These direct measurements were conducted during single-pass FSP runs using a Densimet 176 tool with a shoulder diameter of $28.6 \mathrm{~mm}$. The pin was in the shape of a truncated cone $12.7 \mathrm{~mm}$ in length, having a base diameter of $15 \mathrm{~mm}$, a tip diameter of $6.3 \mathrm{~mm}$, and a stepped-spiral feature on its surface. The FSP runs were typically conducted at 1000 to $1200 \mathrm{rpm}$ and at a traversing rate of either 50.8 or $152.4 \mathrm{~mm} \mathrm{~min}^{-1}$ on plates initially at room temperature, although one run was conducted after the plate was preheated to a temperature $T=400{ }^{\circ} \mathrm{C}$. Plate dimensions were approximately $300 \times 150 \times 19 \mathrm{~mm}^{3} \quad$ (length $\times$ width $\times$ thickness), and the temperature cycles in all cases were consistent with Rosenthal's analytical solution for heat flow due to a point source of heat moving on the surface of a semiinfinite solid. ${ }^{[6]}$ Thus, heating from the initial plate temperature to the peak temperature was rapid upon approach of the tool to the thermocouple location, while cooling after passage of the tool was at a lower rate. Also, heating and cooling rates decreased as the 
traversing rate decreased or preheating temperature increased, while dwell times correspondingly increased. Measured dwell times above $T \approx 1173 \mathrm{~K}\left(900^{\circ} \mathrm{C}\right)$ ( $T \approx 0.9 T_{\text {melt }}$ ) varied from 2.2 to 8.7 seconds for such processing conditions. ${ }^{[5]}$

The as-cast NiAl bronze material of interest in these investigations exhibits a characteristic series of phase transformations ${ }^{[5,7-22]}$ that commence as the temperature increases above $T \approx 0.8 \quad T_{\text {melt }}(T \approx 1073 \mathrm{~K}$ $\left(800{ }^{\circ} \mathrm{C}\right)$ ), so dwell times at such temperatures as well as the local peak temperature will be factors determining the extent to which such transformations attain equilibrium. A procedure involving quantitative analysis of stir zone microstructures resulting from FSP-induced transformations was used to assess local peak temperatures in this alloy. ${ }^{[20,22]}$ This assessment was accomplished using an empirical relationship between experimentally determined constituent volume fractions and annealing temperature in samples from the same alloy after isothermal equilibration in the $\alpha+\beta$ phase field. The stir zone measurements were in good agreement with the thermocouple data despite the very brief dwells typical of the FSP runs, and it was suggested in an earlier investigation that the concurrent straining during FSP thermomechanical cycles serves to accelerate the phase transformations that occur upon heating of this alloy. ${ }^{[5,20,22]}$ Indeed, concurrent straining during hot torsion of a pearlitic eutectoid steel was shown to accelerate the spheroidization rate by a factor of $\approx 10^{4}$.23-25] $^{\text {Such a reaction is controlled by interstitial }}$ $\mathrm{C}$ diffusion, while all of the transformations in $\mathrm{NiAl}$ bronze involve diffusion of substitutional elements; thus, a less remarkable acceleration of the phase transformations might be expected.

Direct determination of the full strain and strain-rate fields during FSP is infeasible, although models of the deformation field suggest that local values of the equivalent strain, $\varepsilon_{e q}$, may attain 10 or greater and the corresponding local strain rate, $\dot{\varepsilon}$, may be on the order of $10^{2} \mathrm{~s}^{-1}$. ${ }^{[26,27]}$ The NiAl bronze material of interest in the present study develops a duplex $\alpha(\mathrm{fcc}) / \beta$ (bcc) stir zone microstructure during FSP, and these two phases apparently deform in a compatible manner. Because the transformation products of the $\beta$ are readily distinguished from the $\alpha$ phase upon cooling to ambient temperature after FSP, the observed distortion of the constituents in the resulting microstructure may enable estimation of the local strains as well as the local peak temperature. Local strains in the TMAZ were estimated from the apparent distortions of the primary Al constituent in a cast Al-7 wt pet. Si alloy after FSP. ${ }^{[28]}$ This article will report on an investigation into the estimation of strain from distortion of microstructure constituents and also show that concurrent deformation accelerates the rate of dissolution of the eutectoid constituent upon heating during FSP of an NiAl bronze material.

\section{EXPERIMENTAL PROCEDURES}

The NiAl bronze plates of this investigation were described previously ${ }^{[19-22]}$ and in Section I. They were sectioned from a large marine casting and then machined to nominal dimensions of $300 \mathrm{~mm}$ in length $\times 150 \mathrm{~mm}$ in width $\times 19 \mathrm{~mm}$ in thickness. The material conforms to UNS95800 and alloy composition data are provided in Table I. Details of the thermocouple placement, time constant values, temperature measurement procedures, and measurement repeatability were also described in a previous publication. ${ }^{[5]}$ Briefly, three sheathed and grounded type $\mathrm{K}$ thermocouples of $1.6 \mathrm{~mm}$ in diameter were placed so that the thermocouple tips were $6.35 \mathrm{~mm}$ (one-half of the pin length) beneath the plate surface at a location corresponding approximately to the center of the tool traverse. One thermocouple was placed along the centerline of the intended tool path, while the other two were placed in a staggered arrangement along the intended tool path and offset by $2.9 \mathrm{~mm}$ to either side of the centerline. This placement was intended to enable assessment of temperature variation across the stir zone from the advancing side (tangential velocity of a point on the tool surface adds to the traversing velocity) to the retreating side (tangential velocity of a point on the tool surface subtracts from the traversing velocity). Optical microscopy examination after FSP revealed that the advancing and centerline thermocouples were displaced toward the retreating side, while the retreating side thermocouple was essentially unaffected. For this reason, the retreating side data were used here for analysis of microstructure in relation to the measured stir zone thermal cycle.

A separate single-pass (i.e., bead-on-plate) FSP run, approximately $200 \mathrm{~mm}$ in length, was conducted on one of these plates. The plate was initially at room temperature with FSP at $1000 \mathrm{rpm}$ and $50.8 \mathrm{~mm} \mathrm{~min}^{-1}$ using a Densimet 176 (PLANSEE - USA, Franklin, MA) tool tilted 3 deg away from the direction of tool advance. The tool was identical in design to those used to obtain the direct thermocouple measurements. Here, the traverse was terminated approximately $30 \mathrm{~mm}$ from the end of the plate by lifting the tool from the plate.

The as-processed plate was sectioned through the pin extraction site at the end of the tool traverse in order to reveal the plane parallel to the plate surface at the middepth of the stir zone. This is illustrated in the schematic of Figure 1. For optical microscopy, grinding and polishing were followed by etching in a two-step process involving, first, immersion for 1 to 2 seconds in a

Table I. Composition Data (Weight Percent) for NiAl Bronze (UNS95800)

\begin{tabular}{|c|c|c|c|c|c|c|c|}
\hline Element & $\mathrm{Cu}$ & $\mathrm{Al}$ & $\mathrm{Ni}$ & $\mathrm{Fe}$ & $\mathrm{Mn}$ & $\mathrm{Si}$ & $\mathrm{Pb}$ \\
\hline Min-Max & $79.0(\mathrm{~min})$ & 8.5 to 9.5 & 4.0 to 5.0 & 3.5 to 4.5 & 0.8 to 1.5 & $0.10(\max )$ & $0.03(\max )$ \\
\hline Nominal & 81 & 9 & 5 & 4 & - & - & - \\
\hline Alloy & 81.3 & 9.17 & 4.46 & 3.68 & 1.24 & 0.06 & $<0.005$ \\
\hline
\end{tabular}




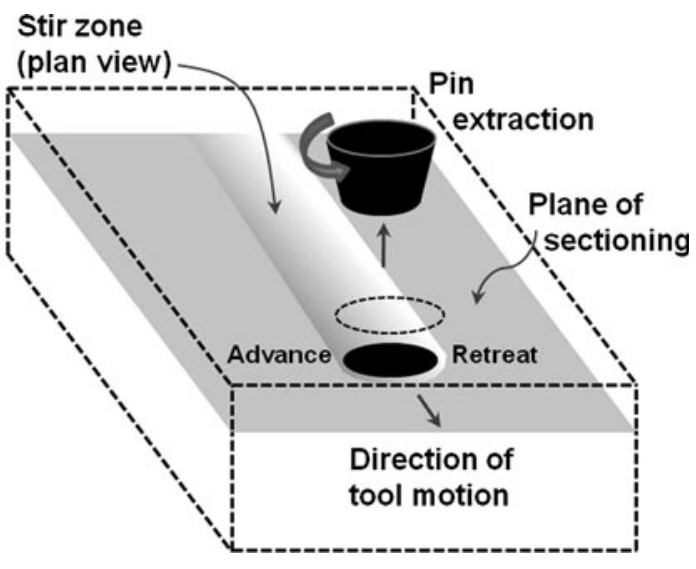

Fig. 1-Schematic diagram showing the plane (shaded) of the metallographic section in the plate at the pin extraction site at the end of the FSP traverse.

solution of $40 \mathrm{~mL}$ water- $40 \mathrm{~mL}$ ammonium hydroxide$2 \mathrm{~mL}$ hydrogen peroxide (30 pct) and rinsing in water, followed by, second, immersion for 1 to 2 seconds in a solution of $60 \mathrm{~mL}$ water-30 mL phosphoric acid-10 mL hydrogen peroxide. Etched samples were examined using bright-field illumination in a NIKON EPIPHOT 200* inverted microscope equipped with a CCD camera

*NIKON EPIPHOT 200 is a trademark of Nikon Instruments, Inc., Melville, NY.

and digital image analysis system. For scanning electron microscopy (SEM), the samples were electropolished at a voltage of $15 \mathrm{~V}$ for 5 to 10 seconds in a nitric acidmethanol solution containing 30 pet nitric acid kept at a temperature of $0{ }^{\circ} \mathrm{C}$. All SEM work was carried out on a ZEISS NEON $40^{* *}$ field emission scanning electron

**ZEISS NEON 40 is a trademark of Carl Zeiss SMT, Inc., Peabody, MA.

microscope (FE-SEM) at an accelerating voltage of $20 \mathrm{kV}$ in either secondary or backscattered electron imaging modes.

The as-cast NiAl bronze comprises mainly coarse primary $\alpha$ and a lamellar eutectoid constituent formed during near-equilibrium cooling at rates $\approx 10^{-3} \mathrm{~s}^{-1}$. The latter forms by the eutectoid decomposition reaction $\beta \rightarrow \alpha+\kappa_{\mathrm{iii}}(\mathrm{NiAl})$ and tends to revert to form the $\beta$ phase upon heating in locations where the local peak temperature exceeds the eutectoid range for this alloy. Because subsequent cooling rates are $\approx 2$ to $3 \times 10^{1}{ }^{\circ} \mathrm{C} \mathrm{s}^{-1}$, the cooling transformation products of such FSP-induced $\beta$ are much finer than those in the ascast material and, so, can be readily distinguished in the stir zone microstructure.

Here, quantitative microstructure analysis was conducted to determine the gradients in the local strain and the volume fractions of the various microstructure constituents, including the transformation products of $\beta$ resulting from the FSP thermomechanical cycle. During FSP, the $\alpha$ and the eutectoid regions in the ascast material experience gradients in both deformation and temperature, with the regions closest to the tool pin extraction site being most severely affected. Methods used to determine the local strain and strain gradients will be introduced later in this article. Quantitative assessment of the variation in volume fractions of all of the microstructure constituents as a function of distance from the pin extraction site outward to unaffected material was conducted on micrographs obtained by the FE-SEM examination. The volume fraction of the $\alpha$ phase was found to be more convenient to determine than that of the multiphase regions, since the eutectoid regions in the as-cast material partially revert to $\beta$ as the temperature rises through the eutectoid range and full transformation to $\beta$ requires substantially higher temperatures. Furthermore, subsequent transformation (through various processes) to mixtures of $\alpha+\kappa_{\mathrm{iii}}$ takes place as the alloy cools. Volume fractions were determined by point counting using montages consisting of long strips of images encompassing regions approximately $1300 \mu \mathrm{m} \times 40 \mu \mathrm{m}$ in size. The long dimensions of these montages were perpendicular to the tool diameter and also nearly perpendicular with the direction of tool advance. Two independent sets of measurements on either side of the axis of the tool traverse directions were obtained and are included in this report. As detailed later, local strain data were also acquired from these microstructures, enabling both strain and volume fraction to be correlated.

In an earlier work, ${ }^{[5,22]}$ the relationship between the equilibrium volume fraction of the $\beta$ phase as a function of temperature in the two-phase field in the same alloy was established by annealing experiments involving prolonged heating at temperatures varying from $1033 \mathrm{~K}$ to $1273 \mathrm{~K}\left(760{ }^{\circ} \mathrm{C}\right.$ to $\left.1000{ }^{\circ} \mathrm{C}\right)$ that was followed by water quenching, and the relationship between the temperature, $T$, and $V_{\beta}$ was found to be

$$
\mathrm{T}=244 \mathrm{~V}_{\beta}+758, \quad{ }^{\circ} \mathrm{C} \text { for } 0<\mathrm{V}_{\beta}<1
$$

In previous investigations, this relationship was used to estimate peak temperatures by applying the same quantitative microstructure analysis methods at selected stir zone locations under the assumption that concurrent deformation during FSP accelerates the reversion of the eutectoid and results in equilibrium $\alpha+\beta$ microstructure mixtures.

Here, the role of FSP in acceleration of phase transformation is examined in detail. Quantitative microstructure analysis was conducted as a function of distance along the tool traversing direction ahead of the pin extraction site to determine the dependence of $V_{\beta}$ on distance ahead of the tool. These measurements and the experimentally determined temperature profile during FSP on an identical sample are then correlated. Further, this correlation can be combined with estimates of local strain based on distortion of the microstructure constituents in a region of a rapid temperature transient and steep strain gradient. In this way, the synergistic effects 
of high temperatures, strains, and strain rates during FSP of the multiphase microstructure in nickel-aluminum bronze may be evaluated.

\section{RESULTS}

The as-cast NiAl bronze microstructure is shown at two different magnifications in the optical micrographs of Figure 2. This microstructure developed during very slow, near-equilibrium cooling at rates on the order of $\approx 10^{-3} \mathrm{~s}^{-1}$ during casting of a large marine component. Details of the constitution and transformations that occur in $\mathrm{NiAl}$ bronze have been given elsewhere. ${ }^{[7-22]}$ Material conforming to the UNS95800 composition in Table I solidifies at $\approx 1323 \mathrm{~K}\left(1050{ }^{\circ} \mathrm{C}\right)$ as a bcc $\beta$ phase. During slow cooling, the primary $\alpha$ fcc terminal solid solution begins to form in the $\beta$ with a Widmannstätten morphology at about $1273 \mathrm{~K}\left(1000{ }^{\circ} \mathrm{C}\right)$. Globular $\kappa_{\mathrm{ii}}$ particles start precipitating in the $\beta$ at about $1203 \mathrm{~K}$ $\left(930{ }^{\circ} \mathrm{C}\right)$, while finer $\kappa_{\mathrm{iv}}$ particles begin to form in the primary $\alpha$ at about $860{ }^{\circ} \mathrm{C}$. During cooling, the volume fraction of $\beta$ decreases approximately linearly with temperature until the eutectoid decomposition reaction $\beta \rightarrow \alpha+\kappa_{\mathrm{iii}}$ occurs over the temperature range of $1073 \mathrm{~K}$ to $1033 \mathrm{~K}\left(800{ }^{\circ} \mathrm{C}\right.$ to $\left.760{ }^{\circ} \mathrm{C}\right)$.

In Figure 2(a), the Widmannstätten morphology of the primary $\alpha$ grains is evident in their elongated, ellipsoidal appearance. Mean values of the corresponding major and minor axis lengths of these grains were determined to be 425 and $175 \mu \mathrm{m}$, respectively. Details of the lamellar structure of the eutectoid constituent as well as the dispersed particles within the primary $\alpha$ are apparent in Figure 2(b). The fine dispersed particles in the primary $\alpha$ are the $\kappa_{\text {iv }}$ phase, which is nominally $\mathrm{Fe}_{3} \mathrm{Al}$ having a $\mathrm{DO}_{3}$ structure. The primary $\alpha$ grains are embedded in a eutectoid constituent consisting of $\alpha$ and lamellar $\kappa_{\text {iii }}$ phase, which is nominally NiAl having a B2 structure. The coarser globular particles of the $\kappa_{\mathrm{ii}}$ phase, which also is nominally $\mathrm{Fe}_{3} \mathrm{Al}$, are dispersed throughout the eutectoid constituent. The globular $\kappa_{\mathrm{ii}}$ particles vary in size from 1.0 to $10.0 \mu \mathrm{m}$, and careful inspection reveals that these particles have a complex structure consisting of an $\mathrm{Fe}_{3} \mathrm{Al}$ "core" and an NiAl "mantle" that is contiguous with the lamellar $\kappa_{\text {iii }}$ NiAl phase. Such a structure is illustrated in Figure 2(c).

The microstructure ahead of the tool at the pin extraction site is shown in Figure 3. The tool moves from left to right at this location, and the field of view in this micrograph extends a distance of approximately $5 \mathrm{~mm}$ from the front edge of the pin extraction site (on the left-hand side of the image) into base metal (on the right-hand side of the image). About $3 \mathrm{~mm}$ ahead of the tool, the eutectic constituent appears to begin to darken. This reflects the onset of the eutectoid reversion reaction $\alpha+\kappa_{\mathrm{iii}} \rightarrow \beta$ due to heating to temperatures above
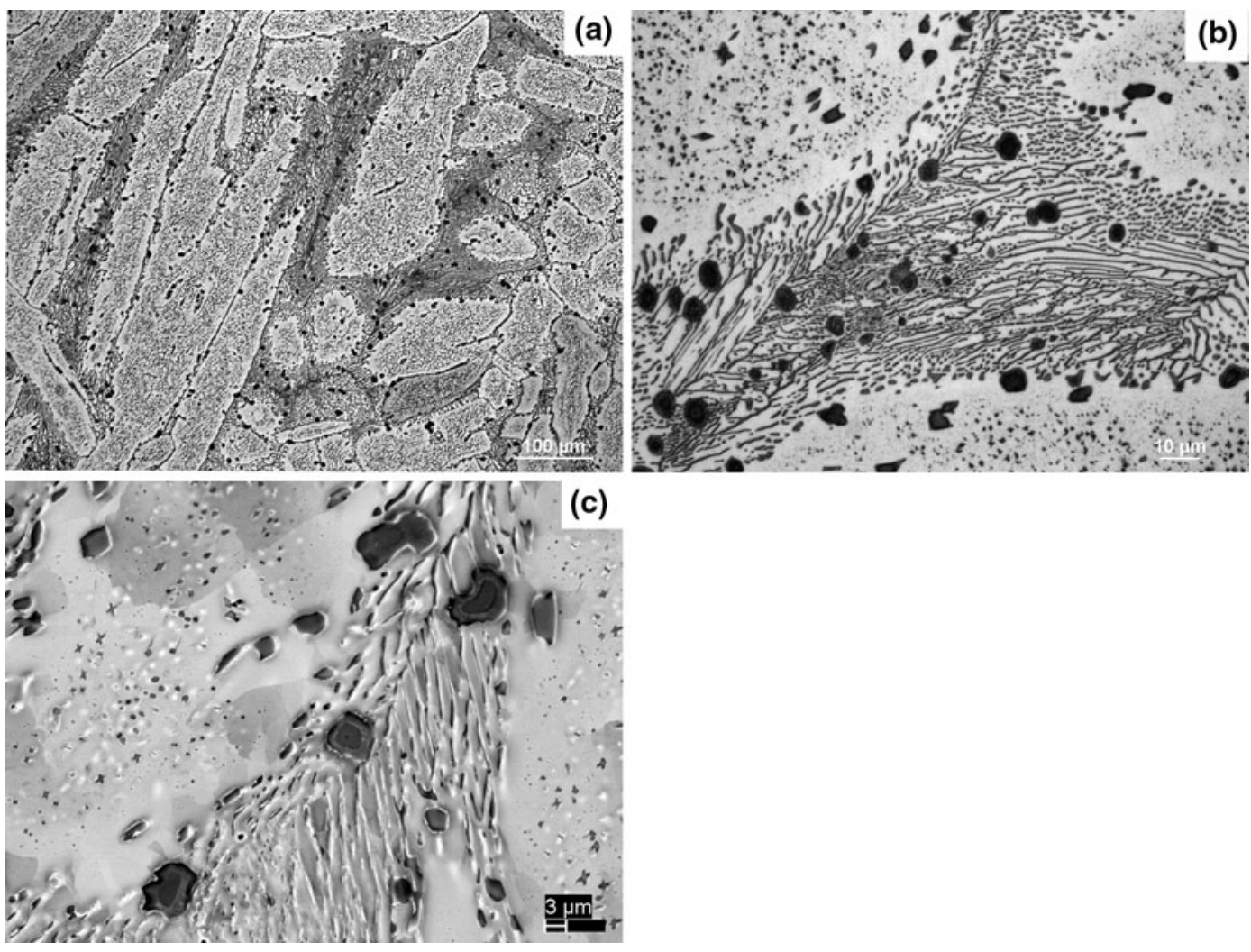

(c)

Fig. 2-(a) and (b) Optical micrographs showing the microstructure constituents in the as-cast NiAl bronze alloy. The primary $\alpha$ is light etching in these micrographs. The Widmanstätten morphology of the primary $\alpha$ and the lamellar eutectoid are shown at low magnification in (a). Fine $\kappa_{\mathrm{iv}}$ precipitates are in the primary $\alpha$, and coarser globular $\kappa_{\mathrm{ii}}$ particles are dispersed mainly in the eutectoid. These constituents are shown at higher magnification in (b). (c) Backscattered electron image showing the complex, multiphase layered structure of the globular $\kappa_{\mathrm{ii}}$ precipitates. 
$1033 \mathrm{~K}\left(760^{\circ} \mathrm{C}\right)$, and the darker appearance reflects the refined transformation products of this $\beta$ due to rapid cooling after cessation of processing and extraction of

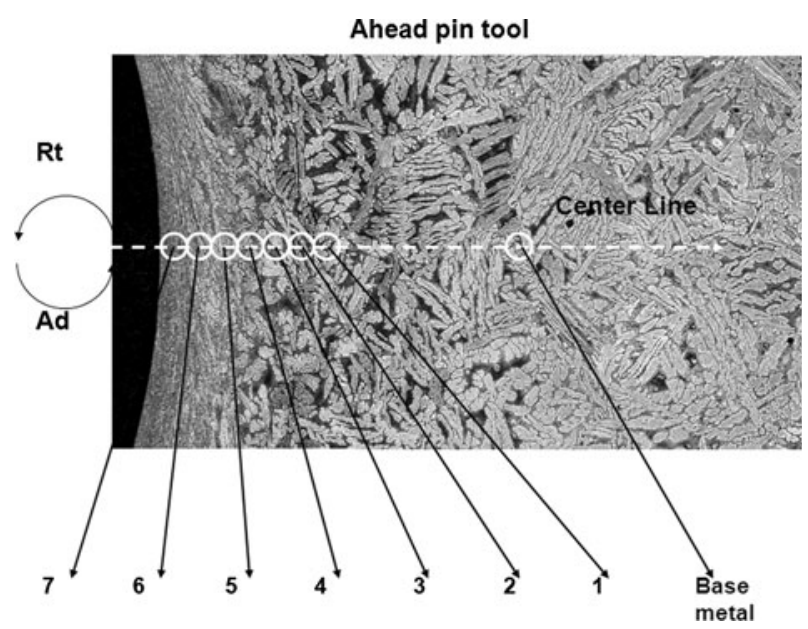

Fig. 3-Montage of optical micrographs shows the plan view of the microstructure ahead of the FSP tool extraction site. The edge of the pin extraction site is located to the left and the tool rotation and traversing directions are indicated; locations of subsequent micrographs relative to the tool extraction site are also indicated. the tool. In the region extending from $3 \mathrm{~mm}$ downward to approximately $1 \mathrm{~mm}$ from the edge of the pin extraction site, microstructure evolution appears to be dominated by reversion of the eutectoid, and both the primary $\alpha$ and the $\beta$ transformation products appear undistorted by the action of the tool. Deformation becomes apparent about $1 \mathrm{~mm}$ ahead of the tool. This is reflected in the evident shearing distortion of both the primary $\alpha$ and $\beta$ transformation products, suggesting that the $\alpha$ and $\beta$ phases deform compatibly at the temperatures attained in this region. However, the relative fractions of the primary $\alpha$ and the $\beta$ transformation products cannot be discerned at the low magnification of the micrograph in Figure 3.

Successive stages in the reversion reaction within the heat affected zone (HAZ; locations 1 through 3 in Figure 3) are shown at higher magnification in Figure 4. At the HAZ location most distant from the tool extraction site (location 1; Figure 4(a)), individual $\kappa_{\mathrm{iii}}$ lamella in the interior of the eutectoid constituent appear to be dissolving into the adjacent $\alpha$. Also, the $\kappa_{\mathrm{iii}} \mathrm{NiAl}$ outer layer on the globular $\kappa_{\mathrm{ii}}$ may be reacting with the surrounding $\alpha$. Figure 4(b) was obtained at location 2, where a higher local peak temperature led to dissolution of the lamellar $\kappa_{\mathrm{iii}}$ to form $\beta$ in the interior of the eutectoid region in the micrograph. Fine Widmanstätten $\alpha$ and other transformation products then
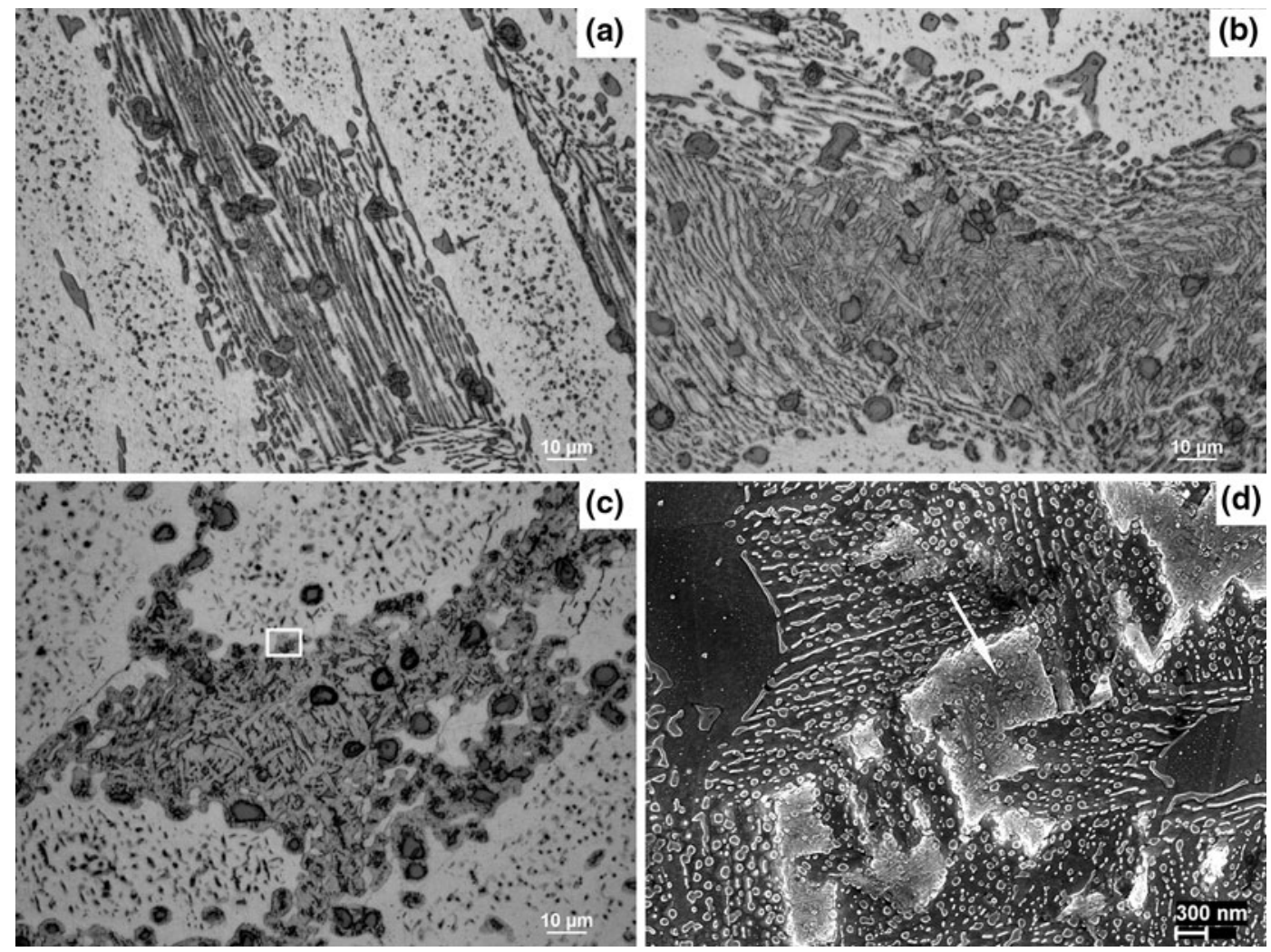

Fig. 4-(a) through (c) HAZ micrographs (optical) at locations 1, 2, and 3 in Fig. 3, respectively. Note the lamellar eutectoid in (a), the dissolution of the lamellar eutectoid in the central regions of the original eutectoid in (b), and the complete reversion of the original lamellar eutectoid in (c), at locations progressively closer to the tool along the axis of tool advance. In (c), the lamellar eutectoid regions reverted to $\beta$ during the FSP thermomechanical cycle and then subsequently transformed back into an $\alpha+\kappa$ mixture upon rapid cooling after tool extraction. (d) Secondary electron image from a region as that indicated by the box in (c) showing fine lamellar eutectoid and bainitic regions (indicated by the white arrow) formed by transformation of $\beta$ at high cooling rates. 
formed from this $\beta$ on subsequent cooling. Also, the $\mathrm{NiAl}$ outer layer on the $\kappa_{\mathrm{ii}}$ dissolved completely in this region of the eutectoid constituent. Still closer to the tool at location 3 (Figure 4(c)), the lamellar structure of the eutectoid constituent in as-cast material is no longer evident. The $\beta$ formed during heating transformed on subsequent cooling, and the Widmanstätten $\alpha$ in this constituent is somewhat coarser than that evident in Figure 4(b). Examination of Figure 4(c) also shows that the $\kappa_{\mathrm{iv}}$ particles also began to dissolve into the primary $\alpha$ so that the local peak temperature exceeded $860{ }^{\circ} \mathrm{C}$.

The secondary electron image in Figure 4(d) was obtained from a location within the $\beta$ transformation products in Figure 4(c). Prior investigations of FSPinduced microstructures in NiAl bronze by transmission electron as well as optical microscopy methods documented the cooling transformation products of $\beta$ formed after heating just above the solvus temperature for $\kappa_{\text {iv }}$. During cooling at rates of $10^{1} \mathrm{C} \mathrm{s}^{-1}$ or faster, these transformation products develop in the following sequence: Widmanstätten $\alpha$; refined $\alpha+$ lamellar/particulate $\kappa_{\mathrm{iii}}$; bainitic $\alpha+\kappa_{\mathrm{iii}}$; and, at the highest cooling rates, martensitic $\beta \cdot{ }^{[19,20]}$ Here, this high-resolution FE-SEM image shows a refined $\alpha+$ lamellar/particulate $\kappa_{\mathrm{iii}}$ and the bainitic $\alpha+\kappa_{\mathrm{iii}}$ in this location. The bainitic $\alpha+\kappa_{\mathrm{iii}}$ (indicated by the arrow in Figure 4(c)) is thought to be distinguished by transformation of $\beta$ to $\alpha$ followed by $\kappa_{\text {iii }}$ precipitation in the form of a particulate or other nonlamellar eutectoid decomposition product, while the lamellar eutectoid $\alpha+\kappa_{\text {iii }}$ transformation product reflects precipitation of $\kappa_{\mathrm{iii}}$ followed by formation of $\alpha^{[11,13-17]}$

Within a distance $\approx 1 \mathrm{~mm}$ ahead of the pin extraction site, heating is accompanied by deformation. The corresponding region is the thermomechanically affected zone (TMAZ), and microstructure evolution is shown in Figure 5 for two locations, denoted 4 and 6 in Figure 3, within this region. The pin extraction site is out of the field of view but toward the bottom side of the images in Figure 5. The onset of deformation is evident at the middle of the image (from top to bottom) in Figure 5(a), which is centered on location 4 , and the increasing deformation in the direction of the arrow in this figure is indicated by the shape changes of both phases. In this view, the deformation is apparently shear that is induced by the tool rotation, and the magnitude of the shear increases with decreasing distance to the edge of the pin extraction site. The field of view in Figure 5(b) is centered on location 6 , and this field overlaps that of the lower part of Figure 5(a). At the higher magnification in Figure 5(b), the development of refined grains in the primary $\alpha$ is readily apparent. These grains are 5 to $10 \mu \mathrm{m}$ in size, and a Widmanstätten morphology can also be identified in the transformation products of the $\beta$. Also, the volume fraction of $\beta$ transformation products appears to increase with decreasing distance to the edge of the pin extraction site.

Figure 6 shows TMAZ microstructures for locations 4 through 7 at higher magnification. In Figure 6(a), which is from location 4 at the outer edge of the TMAZ, the fine Widmanstätten morphology in the $\beta$ transformation products indicates that the eutectoid constituent of the as-cast microstructure has fully reverted to form $\beta$ at the local peak temperature. Furthermore, the fine $\kappa_{\text {iv }}$ are continuing to dissolve in the primary $\alpha$. In Figure $6(\mathrm{~b})$, the distortion of the primary $\alpha$ and the $\beta$ transformation products at location 5 indicates that shear deformation commenced. Also, new, fine, and equiaxed grains formed within the primary $\alpha$ at this location. In prior work, the formation of these new grains in the primary $\alpha$ was attributed to particlestimulated nucleation of recrystallization ${ }^{[29-31]}$ associated with the $\kappa_{\text {iv }}$ particles prior to their disappearance. At some locations in Figure 6(b), it appears that the $\beta$ that formed as the $\kappa_{\mathrm{iv}}$ dissolved into the primary $\alpha$ spread along the boundaries of the newly formed $\alpha$ grains. The fine $\alpha$ grains in the primary constituent appear to remain equiaxed even as this constituent sustains increasing shear strains. In Figure 6(c), this is evident in the micrograph from location 6 . Thus, the microstructures developed by the FSP thermomechanical cycle lead to the "banded" appearance in the TMAZ that is evident in Figures 5, 6(b), and 6(c) and that can be described as composed of two regions appearing as
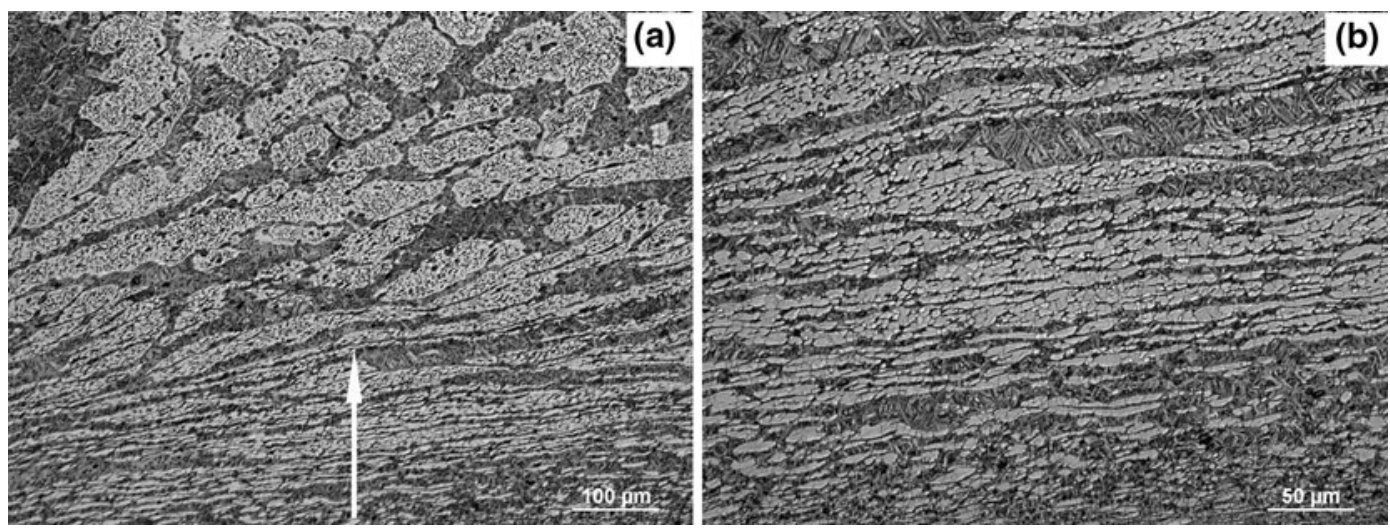

Fig. 5-Optical micrographs from the TMAZ in locations 4 and 6 in Fig. 3 illustrating the effect of deformation at higher temperatures during the FSP thermomechanical cycle. (a) The pin extraction site is near the bottom and the direction of tool traversing is indicated by the arrow. The shape distortion evident as elongation of both the primary $\alpha$ and $\beta$ phases in the tangential sense in the direction of tool rotation shows increasing strain in the TMAZ. (b) Fine $\alpha$ grains can be clearly seen in the primary $\alpha$ in the micrograph from location 6 . 

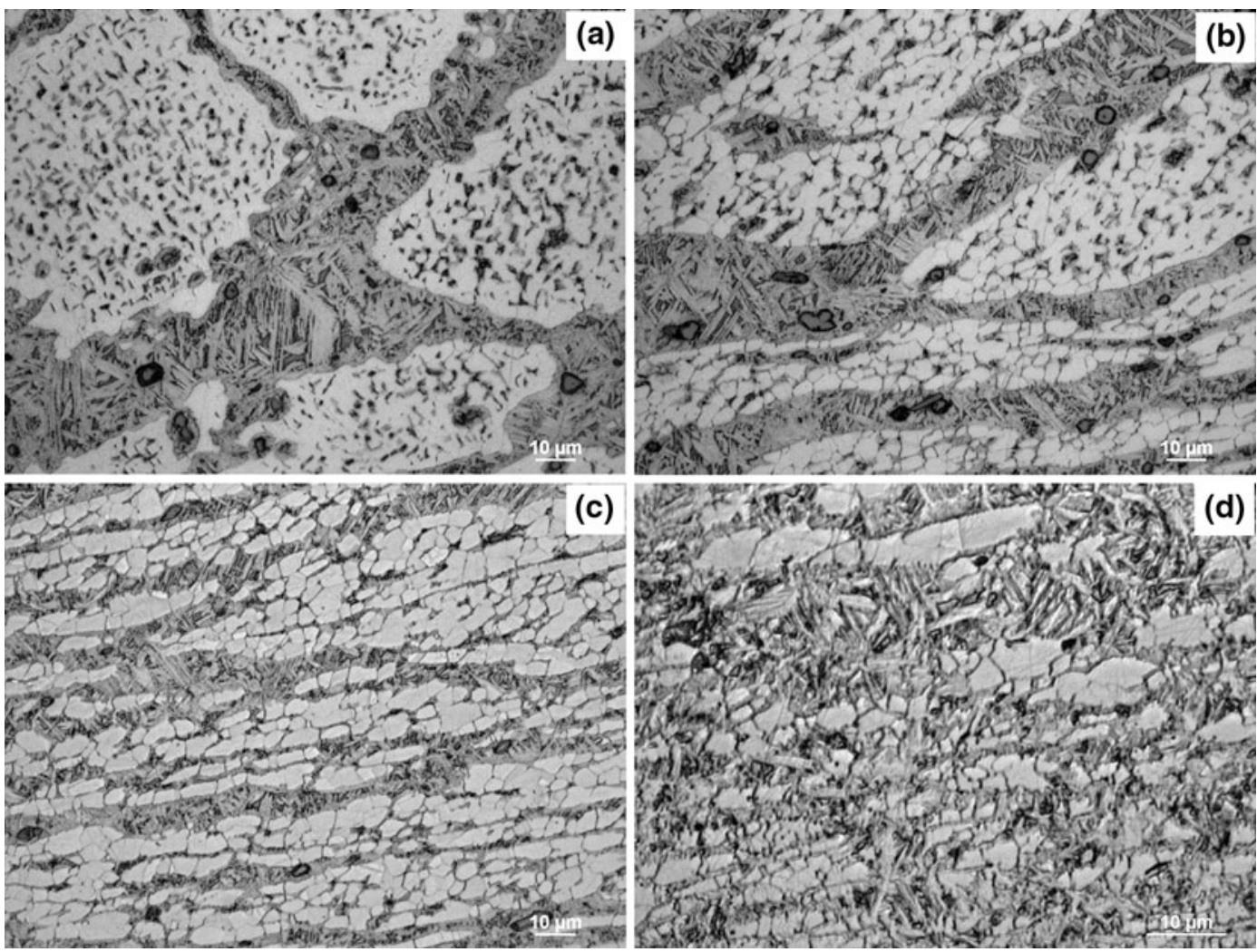

Fig. 6-(a) through (d) Higher magnification optical micrographs from locations 4 through 7 in Fig. 3, respectively. Location (a) has experienced the least deformation, as evidenced from the shape of the primary $\alpha$ phase, but the lamellar eutectoid has undergone complete transformation to $\beta$ and fine Widmanstätten $\alpha$ phase has formed from the $\beta$ during subsequent cooling. In (b), the onset of shear deformation is evident in the distortion of the primary $\alpha$, which also appears to have undergone a recrystallization reaction. The development of a banded microstructure (refer to the text) is shown in (c). Note the dark etching constituents along the fine $\alpha$ boundaries in (b) and (c). The microstructure closest to the tool surface shows a homogenized mixture of $\alpha$ and transformation products of $\beta$.

bright and dark in the optical micrographs. These two regions result from (1) the conversion of large $\alpha$ regions present in the as-cast alloy to a distribution of newly formed equiaxed $\alpha$ grains embedded in a matrix of $\beta$ transformation products producing the predominantly light regions, and (2) large portions of the eutectoid regions in the as-cast alloy transforming to regions of fine $\beta$ transformation products appearing as relatively dark areas.

Figure 6(d) is from location 7, which is closest to the pin extraction site and correspondingly has experienced the largest local strains among this sequence of images. At this location, the two regions in the TMAZ described previously can no longer be separately distinguished. Instead, the primary $\alpha$ appears to have become fragmented and intermixed with the $\beta$ transformation products leading to a very homogeneous microstructure. This fragmentation process may account for the development of extensive regions of fine, equiaxed microstructures in transverse views of stir zones following FSP of NiAl bronze materials.

The backscatter electron image of Figure 7(a) illustrates the onset of deformation at the outer edge of the TMAZ at a site near location 4. Subgrain formation in the primary $\alpha$ is suggested by contrast variation throughout this constituent. Partial reversion of the as-cast eutectoid is also apparent in the interior regions of this constituent, e.g., to the left of center and upper right in this image. Figure 7(b) is from location 5 wherein fine, equiaxed grains have formed in the primary $\alpha$. The $\kappa_{\mathrm{iv}}$ particles appear to have dissolved completely in the primary $\alpha$ and, together with the microstructure shown in Figure 6(b), suggest that grain refinement in the primary $\alpha$ occurs by interaction of the $\mathrm{Fe}$ and $\mathrm{Al}$ components of the $\kappa_{\mathrm{iv}}$ with the evolving deformation structure in the primary $\alpha$. Again, fine Widmanstätten $\alpha$ throughout the $\beta$ transformation product is consistent with full reversion of the as-cast eutectoid constituent. Indeed, the $\beta$ transformation product includes both a fine $\alpha+$ lamellar/particulate $\kappa_{\mathrm{iii}}$ and bainitic $\alpha+\kappa_{\mathrm{iii}}$, as shown in the secondary electron image of Figure 7(c), as well as the Widmanstätten $\alpha$. Thus, as demonstrated here, the $\beta$ phase transforms to both a fine lamellar eutectoid as well as a bainitic product upon rapid cooling after passage of the FSP tool.

\section{DISCUSSION}

In this experiment, the traversing of the tool at a rate of $50.8 \mathrm{~mm} \mathrm{~min}^{-1}$ leads to a correspondence between time and distance ahead of the tool pin extraction site. 

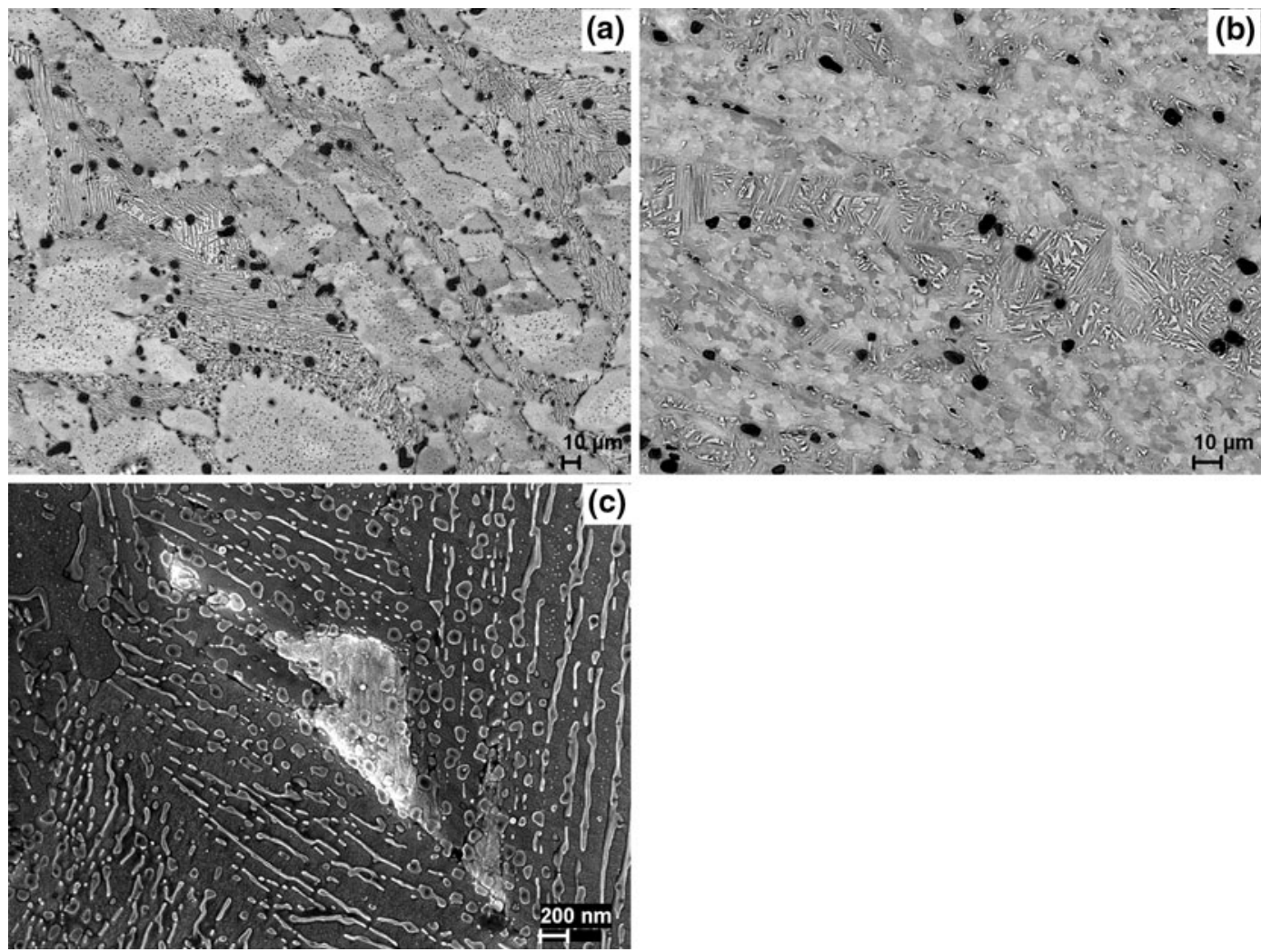

Fig. 7- (a) and (b) Backscattered electron images from regions at the HAZ/TMAZ boundary and well within the TMAZ. (c) Secondary electron image showing the mixture of fine lamellar eutectoid and the bainitic transformation products formed from the $\beta$ phase after FSP.

Thus, a distance of $1 \mathrm{~mm}$ along the indicated centerline of the tool traverse in Figure 3 is equivalent to an elapsed time of $\approx 1.2$ seconds, so the distortion that is apparent ahead of the pin extraction site (Figure 3 and shown in more detail in Figures 5 and 6) occurs over such an elapsed time interval. Furthermore, the micrographs in Figures 3, 5, 6, and 7 illustrate a gradient in distortion, and thus strain, of the microstructure constituents from the base metal ahead of the tool to the tool pin-work piece interface. The strains in this gradient can be estimated approximately if it is assumed that the apparent displacements in these images are confined to the plane of the plate so that the deformation is plane strain in nature. Transverse views of stir zone microstructures in NiAl bronze show that displacements in the TMAZ depend on location along the stir zone periphery and may take place either upward or downward along the pin tool axis. Thus, the strain estimates here will be lower bound in nature.

The as-cast NiAl bronze microstructure shown in Figure 2 may be represented by ellipsoidal primary $\alpha$ grains dispersed in a matrix formed by the eutectoid decomposition reaction $\beta \rightarrow \alpha+\kappa_{\mathrm{iii}}$. This is illustrated in Figure 8(a) wherein the minor and major axes of a primary $\alpha$ grain are denoted by $a_{0}$ and $b_{0}$, respectively. The aspect ratio, $A_{0}$, of the primary $\alpha$ grains is then $A_{0}=a_{0} / b_{0}=0.41$, and simple shear in the TMAZ will distort the primary $\alpha$ so that the minor and major axes become $a$ and $b$, as indicated in Figures 8(b) and (c). Then, the corresponding maximum and minimum principal strains are given by

$$
\varepsilon_{1}=\ln \frac{b}{b_{0}} \text { and } \varepsilon_{3}=\ln \frac{a}{a_{0}}
$$

where $\varepsilon_{1}$ is the maximum principal strain and $\varepsilon_{3}$ is the minimum principal strain, and $\varepsilon_{1}=-\varepsilon_{3}$ for the simple shear displacements in the plane of the plate envisioned in this model. Under this assumption of plane deformation, the aspect ratio of the deformed grains, $A=a / b$, will be given by

$$
A=A_{0} \exp \left(-2 \varepsilon_{1}\right)
$$

wherein all terms were previously defined. Thus, the principal strain, $\varepsilon_{1}$, may be estimated by measuring the aspect ratios of the primary $\alpha$ grains as a function of location ahead of the tool. This approach was taken here by generating montages of images (not shown here), as discussed under Section II. Approximately 25 aspect ratio values were obtained from each montage in two series of montages located in two regions located on either side of the axis of tool advance ahead of the pin extraction site in Figure 3. These aspect ratio values were averaged and the corresponding local maximum principal strain value was then calculated using Eq. [3]. This strain as a function of distance ahead of the tool is plotted in the lower graph of Figure 9 for each region. At the same time, the volume fraction of $\alpha$ was measured 


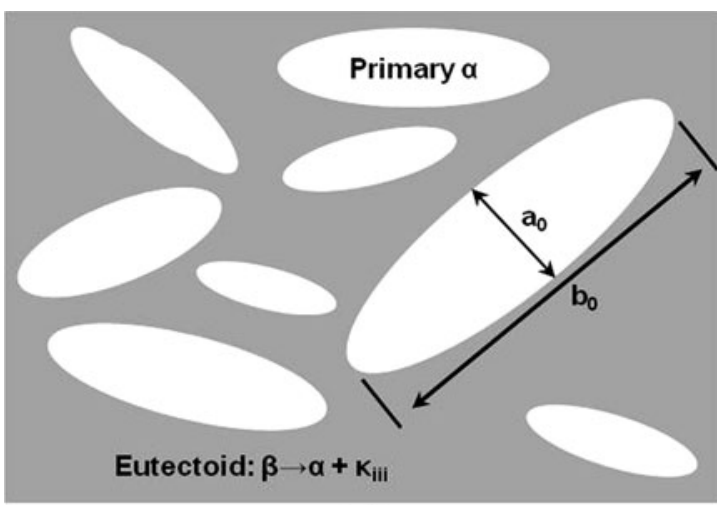

(a)

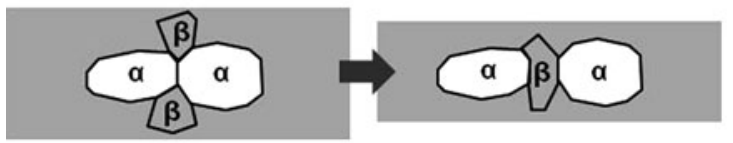

(d)

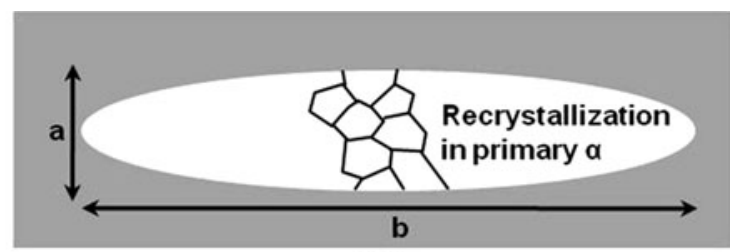

(b)

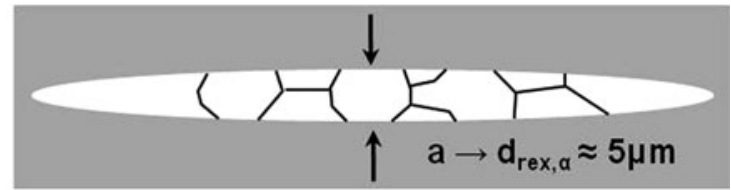

(c)

Fig. 8- Schematic diagrams representing the morphological changes occurring during deformation of the as-cast NiAl bronze are shown. (a) An idealized two-dimensional description of the as-cast condition wherein the primary $\alpha$ is represented by ellipses with minor and major axes denoted by $a_{0}$ and $b_{0}$, respectively, while the eutectoid is represented by the shaded background. $(b)$ through (d) Schematics illustrating the shape distortion, recrystallization, and redistribution of the $\alpha$ and $\beta$ phases with progressive increases in strain (and temperature) during the FSP thermomechanical cycle.

by point counting, as also discussed in Section II, and the resulting volume fraction $(1-\alpha)$ is plotted in the upper graph of Figure 9 for each region. Beyond $4 \mathrm{~mm}$ ahead of the tool, this volume fraction value corresponds to that of the as-cast eutectoid constituent. Partial reversion of this constituent was seen between 2.5 and $4.0 \mathrm{~mm}$, while only FSP-induced $\beta$ transformation products were observed within $2.5 \mathrm{~mm}$ of the tool.

A process of fragmentation of the primary $\alpha$ grains imposes an upper limit to the magnitude of the strains that can be determined by the procedure developed here. Recrystallization within the primary $\alpha$ appears to take place just after the onset of plastic deformation, as may be seen in Figures 6(b) and (c) and in Figures 7(a) and (b). Equiaxed grains $\approx 5 \mu \mathrm{m}$ in size form and apparently remain equiaxed with increasing strains in the TMAZ. This may be seen by comparison of the $\alpha$-phase grains in Figures 6(c) and (d), and, again, in Figures 7(a) and (b). This circumstance is also depicted in the schematic of Figure $8(\mathrm{~b})$. When the thickness of the primary $\alpha$ was reduced to the recrystallized $\alpha$ grain size (Figure $8(\mathrm{c})$ ), the $\beta$ phase appeared to penetrate along the $\alpha / \alpha$ boundaries that are transverse to the major axis of the elongating primary $\alpha$ constituent. Eventually, these transverse $\alpha / \alpha$ boundaries are replaced by $\alpha / \beta$ boundaries, as illustrated in the schematics of Figure 8(d), and the primary constituent can no longer be distinguished. Such a fragmentation process would occur as $a \rightarrow 5 \mu \mathrm{m}$ in Eq. [2] and, thus, at a strain $\varepsilon_{1}=-\varepsilon_{3} \simeq 3.6$. The corresponding aspect ratio would be $A \simeq 3.3 \times 10^{-4}$.

The data in Figure 9 show that reversion of the as-cast eutectoid commences about $4 \mathrm{~mm}$ ahead of the tool and is essentially complete at a distance of $2.5 \mathrm{~mm}$ from the tool. There is no apparent distortion of the primary $\alpha$ at $2.5 \mathrm{~mm}$, so the reversion of the as-cast eutectoid constituent occurs in the absence of deformation

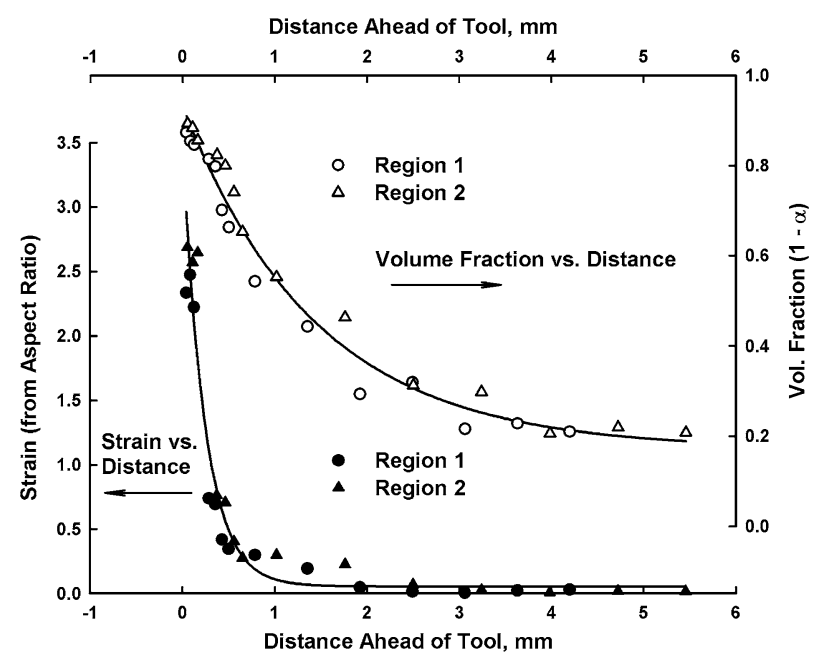

Fig. 9-Plots of calculated strain (filled symbols) and volume fraction of $(1-\alpha)$ (open symbols) along the radial direction parallel to the tool traverse direction at the tool extraction site. The different symbols (circles or triangles) represent two separate measurements along lines on either side of the tool traverse direction.

and, thus, by diffusional processes only in response to the increase in temperature through the eutectoid range of this material. Indeed, the $\kappa_{\mathrm{iii}}$ lamella are nominally $1 \mu \mathrm{m}$ in thickness and separated from one another by 1 to $2 \mu \mathrm{m}$ in Figure 2(b). Distortion of the primary $\alpha$ becomes apparent at about $2.0 \mathrm{~mm}$ ahead of the tool, and thus, the onset of straining apparently reflects the formation of a duplex $\alpha(\mathrm{fcc}) / \beta(\mathrm{bcc})$ microstructure in which both phases deform in a compatible manner. Examination of the strain data in Figure 9 shows that a strain gradient develops so that the strain rate must increase with the tool approach through the deforming volume of material. 
A corresponding increase in the volume fraction $(1-\alpha)$ suggests that the FSP-induced heating results in a corresponding acceleration of the $\alpha+\beta \rightarrow \beta$ transformation in the TMAZ.

Data for temperature as a function of time during FSP of this material at the same traversing rate, $50.8 \mathrm{~mm} \mathrm{~min}^{-1}$, were extracted from the embedded thermocouple measurements reported previously ${ }^{[5]}$ and have been be replotted here in Figure 10 on a distance scale corresponding approximately to the distance ahead of the pin tool in the strain and volume fraction plots. In extracting the data, it was assumed that the peak temperature occurred as the tool came in contact with the retreating side thermocouple. Thus, the temperature as a function of time plot for this thermocouple is assumed to correspond to the temperature transient in the material directly ahead of the pin extraction site along the axis of the tool advance. It is also assumed that the temperature and strain fields are radially symmetric about the tool axis. The representation of temperature as a function of distance ahead of the tool is shown in the upper plot of Figure 10. From the thermocouple measurements, the peak temperature, $T_{P}$, was $1265 \mathrm{~K}$ $\left(992{ }^{\circ} \mathrm{C}\right.$ ), and this is assumed to correspond to the edge of the tool pin extraction site in Figure 3. In the temperature-distance plot, the temperature begins to exceed the eutectoid range $\left(1033 \mathrm{~K}\right.$ to $1073 \mathrm{~K}\left(760{ }^{\circ} \mathrm{C}\right.$ to $\left.800{ }^{\circ} \mathrm{C}\right)$ ) of this quaternary $\mathrm{NiAl}$ bronze material approximately $4.2 \mathrm{~mm}$ ahead of the tool. Indeed, it is at this same distance wherein reversion of the as-cast eutectoid constituent first becomes apparent. This

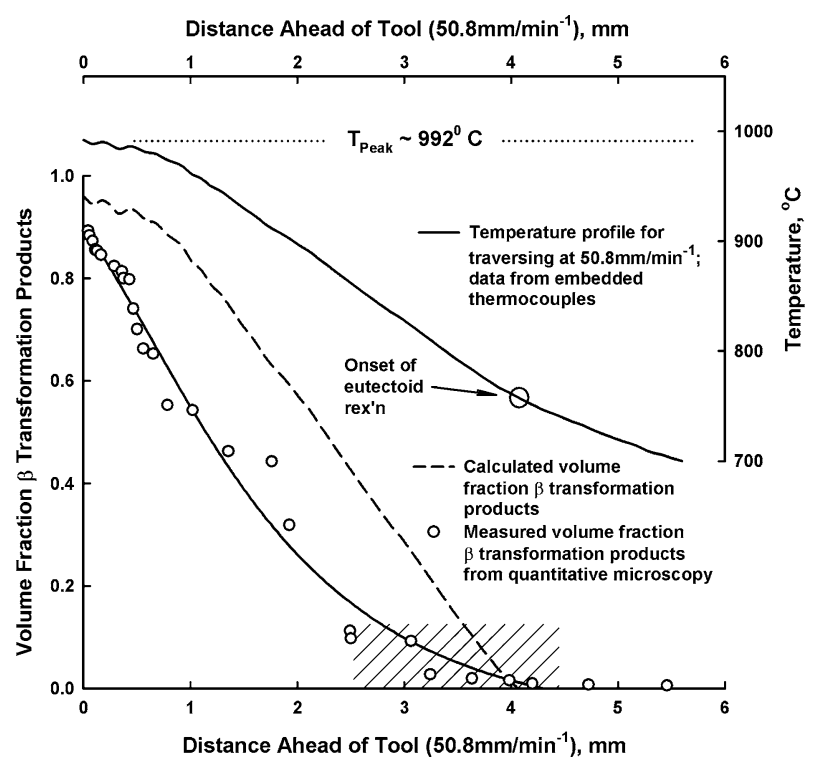

Fig. 10-Effect of local temperature on the volume fraction of the FSP-induced $\beta$-phase transformation products in this NiAl bronze material during FSP. The volume fraction data in the shaded region were modified by subtracting the average volume fraction of the eutectoid in the as-cast material from the experimentally determined value of the total volume fraction of $\beta$ in these regions. The local temperature distribution along the FSP tool traverse direction under identical processing conditions determined in prior work ${ }^{[5]}$ is shown by the continuous line. The dashed line shows the equilibrium volume fraction of $\beta$ calculated from Eq. [1]. gradient in temperature ahead of the tool can be employed to calculate the expected gradient in equilibrium volume fraction of $\beta$ transformation products using Eq. [1]. The calculated volume fraction of $\beta$ transformation products is shown by the dashed line in the middle plot of Figure 10. The observed volume fraction of $\beta$ transformation products was estimated by subtracting the volume fraction of the as-cast eutectoid constituent (volume fraction $(1-\alpha)=0.20)$ from the values of the volume fraction $(1-\alpha)$ obtained beyond $2.5 \mathrm{~mm}$ ahead of the tool in the volume fraction $v s$ distance plot in Figure 9. This distance was estimated based on SEM observations of fully reverted and subsequently transformed $\beta$ decomposition products in the microstructure. The shaded region in Figure 10 indicates the estimated radial distances from the tool, where the eutectoid regions in the microstructure begin and then complete the reversion $\left(\alpha+\kappa_{\mathrm{iii}} \rightarrow \beta\right)$ reaction during FSP. The open symbols in the lower plot of Figure 10 show the resulting gradient in the observed volume fraction of $\beta$ transformation products as a function of distance ahead of the tool.

The data of Figure 10 indicate that the reactions involving reversion of the as-cast eutectoid constituent and the subsequent transformation $\alpha+\beta \rightarrow \beta$ in the resulting duplex structure lag behind the temperature increase associated with adiabatic heating due to the FSP tool. However, these data also show that the formation of $\beta$ is greatly enhanced by the concurrent deformation of FSP, and the volume fraction of $\beta$ appears to approach its equilibrium value, $\approx 0.95$, at the tool pin-work piece interface. In turn, this lends credence to estimates of local peak temperature based on quantitative analysis of stir zone microstructures.

The change in aspect ratio of the primary $\alpha$ constituent indicates that there is a gradient in the corresponding principal strain and that it increases from 0 to a value between 2.5 and 3.0 over a distance of about $2.0 \mathrm{~mm}$. Most of this increase occurs within $0.5 \mathrm{~mm}$ of the tool. In turn, the strain rate may be very roughly estimated to be about $5 \mathrm{~s}^{-1}$ in this region. These strain and strain rate values apply only in the region of the TMAZ wherein the primary $\alpha$ constituent can be discerned. As the recrystallized grains within the primary constituent become intermingled with cooling transformation products of the $\beta$ phase, the primary constituent can no longer be discerned and the strain cannot be estimated in such locations.

Much of the stir zone in regions behind the tool pin consists of a mixture of refined, equiaxed $\alpha$ grains embedded in a fine matrix of $\beta$ transformation products. A typical example of the stir zone behind the tool pin is shown in the micrograph of Figure 11. The primary $\alpha$ and eutectoid constituents of the as-cast microstructure (Figure 2) were replaced here by refined, equiaxed $\alpha$ grains $\approx 5 \mu \mathrm{m}$ in size that are embedded in a matrix of fine transformation products of $\beta$. Such a microstructure suggests that the local equivalent strains exceed 2.5. However, the mechanism(s) responsible for the formation of such a structure during the severe thermomechanical cycle imposed during this process will form the basis for a future publication. 


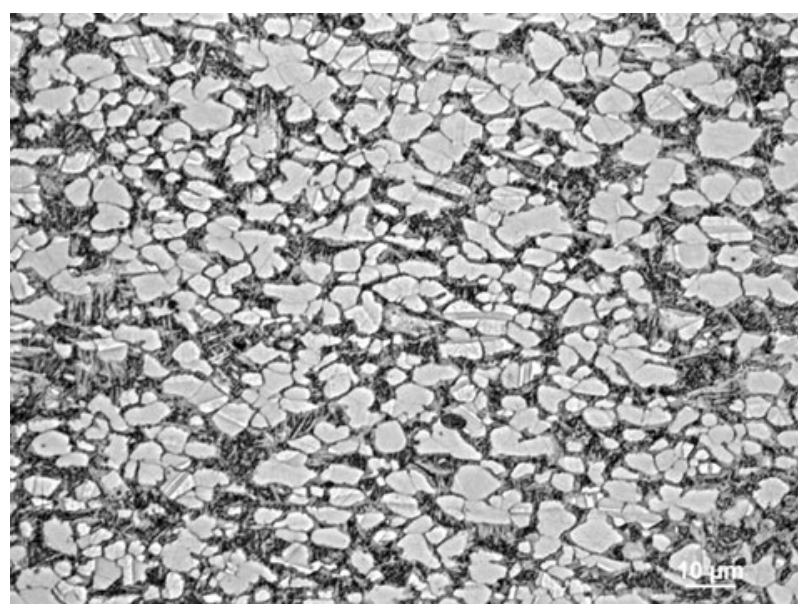

Fig. 11-Optical micrograph illustrating a typical microstructure observed at locations behind the FSP tool in the stir zone showing a duplex microstructure containing fine-equiaxed $\alpha$ grains distributed in a matrix of transformed $\beta$.

\section{CONCLUSIONS}

1) The shape change of the microstructure eutectoid constituents in the thermomechanically affected zone can be used to assess local strain values up to $\varepsilon \approx 3.6$.

2) Concurrent straining accelerates forward (heating) transformations and especially the transformation $\alpha+\beta \rightarrow \beta$ during FSP.

3) This investigation lends credibility to microstructure-based estimates of local peak stir zone temperatures by quantitative microscopy methods.

\section{ACKNOWLEDGMENTS}

The authors acknowledge prior support and funding for this work from the Defense Advanced Projects Agency (DARPA), with Dr. Leo Christodoulou as program sponsor, and current support from the Office of Naval Research (ONR Contract Nos. N00014-06-WR-2-0196 and N00014-09-WR20201), with

Drs. Julie Christodoulou and William Mullins as program officers.

\section{OPEN ACCESS}

This article is distributed under the terms of the Creative Commons Attribution Noncommercial License which permits any noncommercial use, distribution, and reproduction in any medium, provided the original author(s) and source are credited.

\section{REFERENCES}

1. W.M. Thomas, E.D. Nicholas, J.C. Needham, M.G. Murch, P. Templesmith, and C.J. Dawes: G.B. Patent Application No. 9125978.8, Dec. 1991; U.S. Patent No. 5460317, Oct. 1995.

2. R.S. Mishra: in Friction Stir Welding and Processing, R.S. Mishra and M.W. Mahoney, eds., ASM INTERNATIONAL, Materials Park, OH, 2007, pp. 309-50.

3. R.S. Mishra and Z.Y. Ma: Mater. Sci. Eng. R, 2005, vol. 50, pp. 178.

4. J.A. Schneider: in Friction Stir Welding and Processing, R.S. Mishra and M.W. Mahoney, eds., ASM INTERNATIONAL, Materials Park, OH, 2007, pp. 37-49.

5. S. Swaminathan, K. Oh-Ishi, A.P. Zhilyaev, C.B. Fuller, B. London, M.W. Mahoney, and T.R. McNelley: Metall. Mater. Trans. A, 2010, vol. 41A, pp. 631-40.

6. D. Rosenthal: Trans. ASME, 1946, vol. 68, pp. 849-66.

7. P. Weill-Couly and D. Arnaud: Fonderie, 1973, no. 322, pp. $123-$ 35.

8. E.A. Culpan and G. Rose: J. Mater. Sci., 1978, vol. 13, pp. 1647-57.

9. E.A. Culpan and G. Rose: Br. Corr. J., 1979, vol. 14, pp. 160-66.

10. D.M. Lloyd, G.W. Lorimer, and N. Ridley: Met. Technol., 1980, vol. 7, pp. 114-19.

11. P. Brezina: Int. Met. Rev., 1982, vol. 27, pp. 77-120.

12. F. Hasan, G.W. Lorimer, and N. Ridley: Proc. Int. Conf. on Solid to Solid Phase Transformations, TMS, Warrendale, PA, 1982, pp. $745-49$.

13. F. Hasan, A. Jahanafrooz, G.W. Lorimer, and N. Ridley: Metall. Trans. A, 1982, vol. 13A, pp. 1337-45.

14. F. Hasan, G.W. Lorimer, and N. Ridley: J. Phys., 1982, vol. 43, pp. C4 653-C4 658 .

15. A. Jahanafrooz, F. Hasan, G.W. Lorimer, and N. Ridley: Metall. Trans. A, 1983, vol. 14A, pp. 1951-56.

16. F. Hasan, G.W. Lorimer, and N. Ridley: Met. Sci., 1983, vol. 17, pp. 289-95.

17. F. Hasan, J. Iqbal, and N. Ridley: Mater. Sci. Technol., 1985, vol. 1 , pp. $312-15$

18. G.W. Lorimer, F. Hasan, J. Iqbal, and N. Ridley: Br. Corr. J., 1986, vol. 21, pp. 244 48

19. K. Oh-ishi and T. R. McNelley: Metall. Mater. Trans. A, 2004, vol. 35 A, pp. 2951-61.

20. K. Oh-ishi and T. R. McNelley: Metall. Mater. Trans. A, 2005, vol. 36 A, pp. $1575-85$.

21. K. Oh-Ishi, A.P. Zhilyaev, and T.R. McNelley: Metall. Mater. Trans. A, 2006, vol. 37A, pp. 2239-51.

22. T.R. McNelley, K. Oh-Ishi, and A.P. Zhilyaev: in Friction Stir Welding and Processing, R.S. Mishra and M.W. Mahoney, eds., ASM INTERNATIONAL, Materials Park, OH, 2007, pp. 155-73.

23. J.L. Robbins, O.C. Shepard, and O.D. Sherby: J. Iron Steel Inst., 1964, vol. 202, pp. 804-07.

24. O.D. Sherby, B. Walser, C.M. Young, and E.M. Cady: Scripta Metall., 1975, vol. 9, pp. 569-73.

25. B. Walser and O.D. Sherby: Metall. Trans. A, 1979, vol. 10A, pp. 1461-71.

26. A. Askari, S. Silling, B. London, and M.W. Mahoney:, in Friction Stir Welding and Processing, K.V. Jata, M.W. Mahoney, R.S. Mishra, S.L. Semiatin, and T. Lienert, eds., TMS, Warrendale, PA, 2001, pp. 43-54.

27. H.R. Shercliff, P.A. Colegrove, and P.A. Colegrove: in Friction Stir Welding and Processing, R.S. Mishra and M.W. Mahoney, eds., ASM INTERNATIONAL, Materials Park, OH, 2007, pp. $187-217$

28. J.M. García-Infanta, A.P. Zhilyaev, F. Carreño, O.A. Ruano, J.Q. Su, S.K. Menon, and T.R. McNelley: J. Mater. Sci., 2010, vol. 45 (17), pp. 4613-20.

29. F.J. Humphreys: Acta Metall. Mater., 1977, vol. 25, pp. 1323-44.

30. F.J. Humphreys and P.N. Kalu: Acta Metall. Mater., 1987, vol. 35 , pp. 2815-29.

31. R.D. Doherty, D.A. Hughes, F.J. Humphreys, J.J. Jonas, D. JuulJensen, M.E. Kassner, W.E. King, T.R. McNelley, H.J. McQueen, and A.D. Rollett: Mater. Sci. Eng. A, 1997, vol. A238, pp. 219-74. 